\begin{tabular}{l} 
Sharif University of Technology \\
Scientia Iranica \\
SCIENTIA \\
IRAN \\
Thanstions A: Civil Engineering \\
\hline
\end{tabular}

\title{
Prediction of subgrade reaction modulus of clayey soil using group method of data handling
}

\author{
S.A. Naeini ${ }^{a}$, R. Ziaie Moayed ${ }^{a}$, A. Kordnaeij ${ }^{a}$, and H. Mola-Abasi ${ }^{\text {b,* }}$ \\ a. Department of Civil Engineering, Imam Khomeini International University, Qazvin, Iran. \\ b. Department of Civil Engineering, Gonbadekavous University, Gonbadekavous, Iran.
}

Received 15 November 2017; received in revised form 13 May 2018; accepted 6 August 2018

\author{
KEYWORDS \\ Subgrade reaction \\ modulus; \\ Neural network; \\ Plate load test; \\ Group method of data \\ handling; \\ Clay.
}

\begin{abstract}
Settlement-based design of foundations, using subgrade reaction modulus $\left(K_{s}\right)$, is an important technique in geotechnical engineering. Plate Load Test (PLT) is one of the most commonly performed tests to directly obtain $K_{s}$ of soil. As the determination of $K_{s}$ by PLT -especially in greater depths- is both time-consuming and costly, it is necessary to develop models that can easily handle measurable characteristics. The suitability of the Group Method of Data Handling (GMDH) polynomial Neural Network (NN) to estimate $K_{s}$ of clayey soils was investigated in the present research. In order to develop the GMDH models, 123 data sets from Qazvin, Iran, were applied. Predictability of the derived equations was compared with those of other available equations for clayey soil. The results demonstrated that an improvement in predicting $K_{s}$ was achieved. Sensitivity analysis of the best GMDH-based equation showed that the Liquid Limit $(L L)$ of soil was the most influential parameter on the proposed GMDH model in predicting $K_{s}$ of clayey soil.
\end{abstract}

(C) 2020 Sharif University of Technology. All rights reserved.

\section{Introduction}

Geotechnical properties are necessary for evaluating the behavior of geo-materials in any geotechnical project. Owing to the lack of rigorous theoretical formulae between soil parameters and the results of geotechnical tests, the only acceptable method is empirical derivation. In recent years, various laboratory and field investigations have been conducted to understand the complex behavior of soil [1-3].

In engineering works, for the design of structure, instead of modeling the subsoil with all its complexity, a simpler geotechnical parameter called subgrade reaction modulus $\left(K_{s}\right)$ can be employed. $K_{s}$ is the

*. Corresponding author.

E-mail address: hma@gonbad.ac.ir (H. Mola-Abasi)

doi: $10.24200 /$ sci.2018.5586.1357 ratio of applied pressure to the soil through a loading area to the settlement at a given point. The concept of subgrade reaction was introduced by Winkler [4] into applied mechanics. In the model, the assumption is that soil acts as a bed of evenly spaced, independent, and linear springs. It is also assumed that each spring is deformed in response to the vertical stress directly applied to it and no shear stress is transmitted to the adjacent springs [5]. Vesic [6] and Biot [7] proposed $K_{s}$ as a function of relative rigidity of soil and the foundation over it as well as the elastic parameters of the soil. Biot's model, similarly to the theory of elasticity solutions, does not estimate the maximum deflection. Furthermore, Vesic's model does not ensure estimation of the maximum bending moment developed on the footing, treated as a beam on elastic foundation. Iskander and Gabr [8] and Klar et al. [9] made new attempts to analyze soil-pipeline interaction due to tunneling using Vesic's model and Winkler springs to 
predict $K_{s}$. The results showed that the equation might not be suitable for such an analysis. Basudhar et al. [10] developed a new model for expressing Winkler's $K_{s}$, which resulted in simultaneous prediction of the maximum values of bending moment and deflection.

$K_{s}$ is not constant for a given soil and it depends on parameters such as the shape and width of the foundation. Vesic [6] showed that $K_{s}$ depended upon stiffness of the structure and soil, and structures with the same size and different stiffnesses would yield different values of $K_{s}$ for the same applied load. Farouk and Farouk [11] found that determination of $K_{s}$ by neglecting the rigidity of soil-footing system was inappropriate. By neglecting soil plasticity in the linear elastic model, the distribution of $K_{s}$ at the edges is inappropriate. Therefore, in order to get an appropriate distribution of $K_{s}$, the use of nonlinear models is preferred. Terzaghi [12] proposed the following equation for $K_{s}$ in full sized footing in clayey subgrade:

$$
K_{s f}=K_{s} \frac{B_{p}}{B_{f}},
$$

where $B_{f}$ is width of the foundation, $B_{p}$ diameter of the plate, $K_{s f}$ the desired value of subgrade reaction modulus for the full-size foundation, and $K_{s}$ the subgrade reaction modulus for $0.3 \mathrm{~m} \times 0.3 \mathrm{~m}$ bearing plate.

Several researchers have considered some forms of interaction among the spring elements that indicate the soil continuum and have tried to make the Winkler model more realistic and practical [13-18]. Recently, Winkler model has widely been used in soil-structure interaction problems under both dynamic and static conditions [10,19-23].

Plate Load Test (PLT) is one of the most commonly employed tests to directly obtain $K_{s}$ of soil. In PLT, a plate 30 to $45 \mathrm{~cm}$ in diameter is loaded through an incremental multi-step process and the corresponding settlement is monitored step by step (Figure 1). Recently, several researchers used PLT to evaluate $K_{s}$ of soil under certain conditions [22,24-27].

As PLT - especially in great depths - is both time-consuming and costly, efforts have been devoted to proposing empirical equations based on the results of Standard Penetration Test (SPT) [13,28-30].

SPT is one of the most frequently applied field tests in geotechnical investigations. Thanks to its advantages, providing empirical relationships for the prediction of mechanical and compressibility parameters of soil through the results of SPT is an attractive subject in geotechnical engineering. Almost all the available empirical equations to predict soil modulus have been established by using regression analysis [13,24,28-30]. The main drawback of such regression correlations is that they cannot correctly take into account the highly

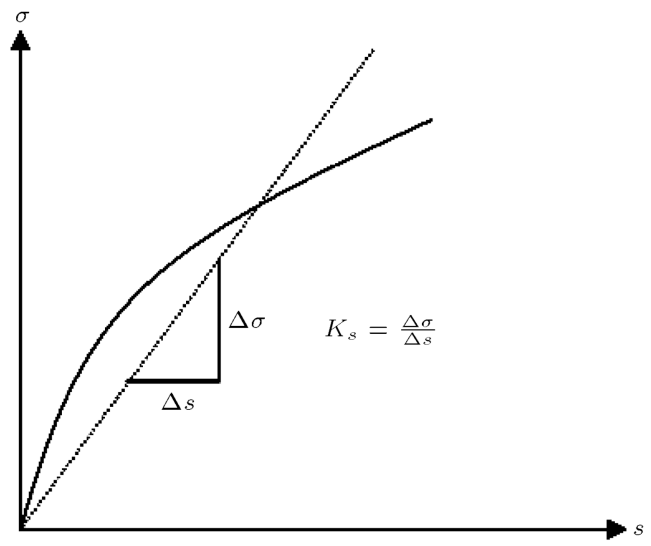

Figure 1. Definition of $K_{s}$ obtained by Plate Load Test (PLT).

nonlinear interactions between $K_{s}$ and soil parameters; therefore, it is necessary to use more advanced methods.

Methods based on Computational Intelligence (CI) - such as fuzzy inference system, support vector machines, artificial Neural Network ( NN), adaptive neuro-fuzzy system, etc. - can be good alternatives to the traditional regression methods. In recent years, CI methods have been used in several geotechnical investigations [31-42]. Although CI methods have a good performance, their main drawback is that they are black box methods and cannot provide equations [43].

The Group Method of Data Handling (GMDH) polynomial NN is a self-organizing approach, with the help of which gradually complex models are produced. Through such models, a set of multi-input singleoutput data pairs $\left(X_{i}, y_{i}\right)(i=1,2, \cdots, M)$ are evaluated. This approach can be used to model complex problems without having specific knowledge of them in hand. GMDH aims to determine the functional structure of a model through empirical data [44]. Using the GMDH, a model can be developed as a set of neurons in which various pairs in each layer are connected via a quadratic polynomial. Thus, they generate new neurons in the next layer. Such a method can be used to process inputs into outputs of the model [45]. Genetic algorithms have been frequently used in the GMDH modeling for each neuron to search for its optimal set of connections with the preceding layer. Various studies have been conducted of GMDH-type NN optimized by genetic algorithms in geotechnical applications in recent years [46-53].

The state of soil at any given time affects $K_{s}$. The higher the density of the soil, the higher the value of $K_{s}$. The organization of soil particles - which refers to the soil structure - is another factor that affects $K_{s}$. The nature of structural bonds of cohesive soil is a function of their origin [54]. As the available equations for prediction of $K_{s}$ of clayey soil do not take into account soil state and effects of nature, simultaneously, in this 
paper, GMDH polynomial NN - optimized by genetic algorithms, which can consider nonlinear behavior of the soil - is developed for predicting $K_{s}$ of clayey soil. In this network, $N_{60}$ is the soil state characteristic and $L L$ and $P I$ represent soil nature or type characteristic.

\section{Review of existing relationships}

The subgrade reaction modulus $\left(K_{s}\right)$ depends upon parameters such as the foundation shape and width as well as the embedment depth of the foundation [55]. Vesic [6] proposed a semi-empirical equation to determine $K_{s}$ in the Winkler model as follows:

$$
K_{s}=\frac{E_{s}}{B\left(1-v^{2}\right)}
$$

This relationship, however, requires Poisson's ratio $(v)$ of the soil and elasticity modulus $\left(E_{s}\right)$, which are difficult to estimate.

PLT is a traditional in situ test to determine $K_{s}$ [12]. The results obtained by PLT allow minimization of the scale factor and soil sample disturbance effects [56]. As it is costly and time-consuming to perform PLT, especially in great depths, some researchers have proposed a simpler empirical equation for various soils, which relates $K_{s}$ to $\operatorname{SPT}\left(N_{60}\right)$. Bowles [29] proposed the following relationship for approximating $K_{s}$ from the allowable bearing capacity $\left(q_{a}\right)$ :

$$
K_{s}=40(S F) q_{a}
$$

Scott [28] proposed the following empirical equation for calculating $K_{s}$ of sandy soil using $\left(N_{60}\right)$ :

$$
K_{s}\left(\mathrm{MN} / \mathrm{m}^{3}\right)=1.8 N_{60}
$$

Ziaie Moayed and Janbaz [57] proposed the following equation for cemented gravelly deposits of Tehran alluvium:

$$
K_{s}\left(\mathrm{MN} / \mathrm{m}^{3}\right)=2.82 N_{60}+79.6 .
$$

Naeini et al. [30] presented the relationship between $K_{s}$ and $N_{60}$ for clayey soils as follows:

$$
K_{s}\left(\mathrm{MN} / \mathrm{m}^{3}\right)=0.96 N_{60}
$$

Dinçer [24] - with the application of a regression analysis - provided the two following relationships between $K_{s}$ and Field Moisture Content ( FMC) and Field Dry Density (FDD) as well as Optimum Moisture Content (OMC) in different compacted soils $(\mathrm{CH}, \mathrm{CL}$, GM, GC, GW, and GP-GM):

$$
\begin{aligned}
K_{s}\left(\mathrm{MN} / \mathrm{m}^{3}\right)= & 362.218-9.432 \mathrm{FMC} \\
K_{s}\left(\mathrm{MN} / \mathrm{m}^{3}\right)= & 150.878-10.93 \mathrm{FMC} \\
+ & 82.419 \mathrm{FDD}+5.921 \mathrm{OMC}
\end{aligned}
$$

Some researchers have proposed correlations between elasticity modulus $\left(E_{s}\right)$ and SPT $[29,58,59]$. Therefore, it is initially necessary to derive $K_{s}$ in terms of $E_{s}$ in accordance with Eq. (1) (Table 1). In Eq. (2), $v$ of soil is set to 0.3 and $B$ of the plate is $305 \mathrm{~mm}$.

\section{Database compilation}

123 datasets of geotechnical investigations in Qazvin, Iran, were employed in the present study. The field tests included SPT and PLT and the laboratory tests included the Atterberg limits and grain size distribution. PLTs were carried out in accordance with ASTM D1194 [60] using rigid circular steel plates with a diameter of $305 \mathrm{~mm}$ and thickness of $25.4 \mathrm{~mm}$. An example of a stress-settlement curve of a PLT performed in this research is depicted in Figure 2. In PLT, the plate is placed at the center of the borehole and then, load is applied to the plate by means of a jack in steps equal to about $20-25 \%$ of the predicted ultimate load. During each loading step, settlement of the plate is observed on dial gauges. At each step of loading, the load is allowed to elapse at least 1 hour. The test will continue until failure, or until the plate

Table 1. $K_{s}-N$ correlations from $E_{s}-N$ relationships using Vesic's equation.

\begin{tabular}{llll}
\hline \multicolumn{1}{c}{$\boldsymbol{E}_{\boldsymbol{s}}$ correlation } & \multicolumn{1}{c}{$\boldsymbol{K}_{\boldsymbol{s}}$ correlation } & \multicolumn{1}{c}{ Soil type } & Reference \\
\hline$E_{s}=0.32 N_{55}+4.8$ & $K_{s}\left(\mathrm{MN} / \mathrm{m}^{3}\right)=1.17 N_{55}+17.6$ & Clayey sand & Bowles [29] \\
$E_{s}=0.33 N_{60}+1.66$ & $K_{s}\left(\mathrm{MN} / \mathrm{m}^{3}\right)=1.2 N_{60}+6.07$ & Clayey sand & Webb $[58]$ \\
$E_{s}=0.3 N_{55}+1.8$ & $K_{s}\left(\mathrm{MN} / \mathrm{m}^{3}\right)=1.1 N_{55}+6.6$ & Silts, sandy silts, or clayey silts & Bowles [29] \\
$E_{s}=0.17 N_{60}$ & $K_{s}\left(\mathrm{MN} / \mathrm{m}^{3}\right)=0.622 N_{60}$ & CL and CL-ML & Behpoor and \\
\hline
\end{tabular}




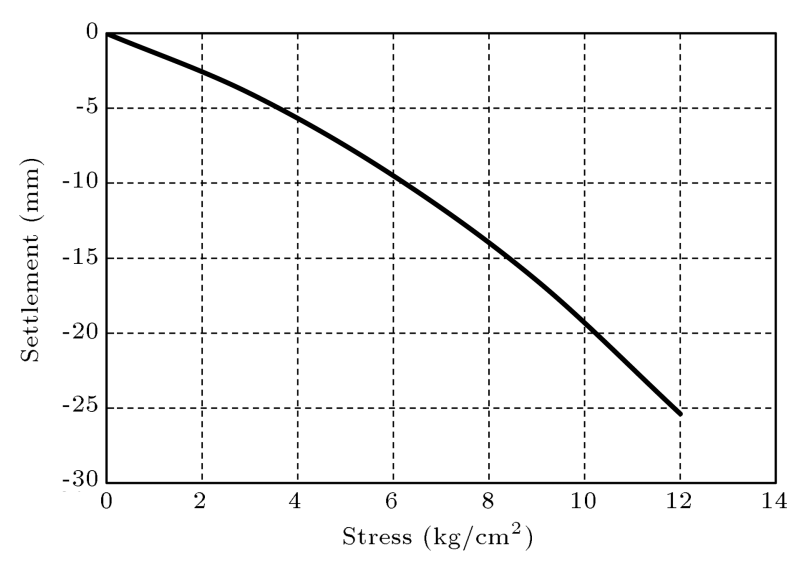

Figure 2. An example of stress-settlement curve derived from a Plate Load Test (PLT).

settles by at least $25.4 \mathrm{~mm}$. In the present article, the secant modulus to the maximum settlement point $(\approx 25.4 \mathrm{~mm})$ was determined as $K_{s}$.

The SPTs were carried out in accordance with ASTM D1586 [61], near the location of each PLT and at the same depth. SPT, contrary to its name, is not completely standard $[62,63]$ and many factors, including test equipment, drilling method, and soil conditions and types affect its results. Therefore, the results of SPT need to be corrected. It must also be mentioned that most of the consultancy firms in Iran use safety hammers and the SPT sampler is not usually fitted with liner. Also, in this study, as the borehole diameter was less than $115 \mathrm{~mm}$, borehole size correction factor was not applied. Another correction factor that can be considered for SPT results is the overburden pressure factor $\left(C_{N}\right)$. However, $C_{N}$ is intended to evaluate the liquefaction potential of sands [61]. Due to undrained condition during the test in fine-grained soil, $C_{N}$ correction factor is not justified $[64,65]$. Therefore, in the present article, the correction of SPT results was carried out for the factors of energy ratio and rod length.

The grain size distribution and Atterberg limits tests were carried out according to ASTM D422 [66] and ASTM D4318 [67], respectively. Figure 3 presents the Grading curves of the used soil samples.

In this study, it is assumed that the soil $K_{s}$ is affected by three parameters: Liquid Limit $(L L)$, Plastic Index $(P I)$, and $\mathrm{SPT}-N_{60}$, as summarized in Table 2. The soils studied are classified as CL

Table 2. Statistical characteristics of databases.

\begin{tabular}{lccc}
\hline Parameter & Min. & Ave. & Max. \\
\hline$L L(\%)$ & 23.2 & 37.5 & 69.3 \\
$P I(\%)$ & 6.2 & 16.1 & 39.2 \\
$N_{60}$ & 9 & 39 & 85 \\
$K_{s}\left(\mathrm{MN} / \mathrm{m}^{3}\right)$ & 21 & 34 & 50 \\
\hline
\end{tabular}

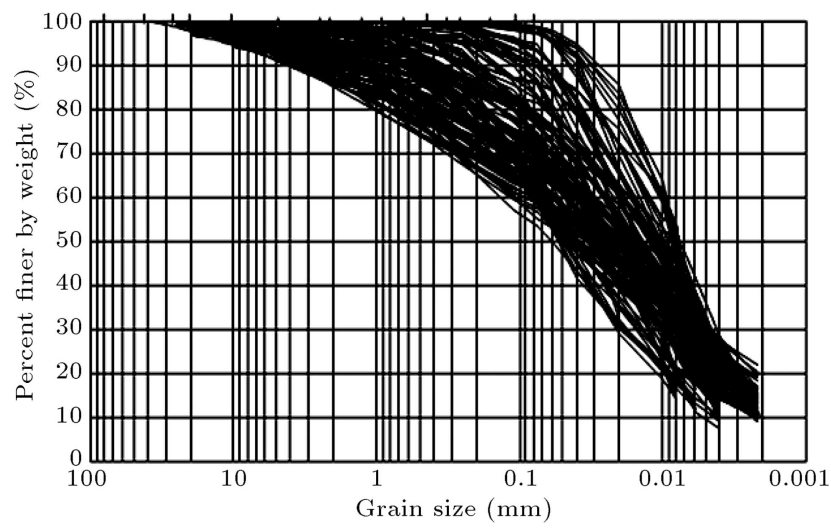

Figure 3. Grading curves of the used soil samples.

and $\mathrm{CH}$ (according to the Unified Soil Classification System). Parameters of the data sets are presented in Figure 4 by frequency histograms. According to Figure 4, the distributions of variables are not uniform. The proposed model is expected to be more accurate in areas with more data densities. The correlation matrix between the soil parameters calculated from the available data set is presented in Table 3 . This makes it difficult to predict $K_{s}$ using a single-variable regression method. Therefore, it is necessary to use a more complex and multi-variable method to predict $K_{s}$.

\section{Estimation of $K_{s}$ by GMDH}

In order to evaluate ability of the GMDH polynomial models to predict $K_{s}$ of clayey soil, the dataset was divided randomly into two separate data sets, including the testing and training datasets. Statistical characteristics of the used soils for modeling of the GMDH are given in Table 4. In terms of statistical characteristics, testing and training datasets are similar. In the present study, among 123 datasets, 20 datasets at the testing stage and 103 datasets at the training stage were used.

Parameters such as the number hidden layers and generations, population size, and crossover and mutation probabilities affect the GMDH prediction. To design the GMDH models in this study, a 100individual-population - with mutation and crossover probabilities of 0.01 and 0.95 - were applied in 300 generations for the population size, to which no further improvement was made. Models without any hidden layer and single-hidden-layer models were evaluated.

Table 3. Correlation matrix of the prediction parameters.

\begin{tabular}{lcccc}
\hline Parameter & $\boldsymbol{L} \boldsymbol{L}$ & $\boldsymbol{P I}$ & $\boldsymbol{N}_{\mathbf{6 0}}$ & $\boldsymbol{K}_{\boldsymbol{s}}$ \\
\hline$L L$ & 1 & 0.94 & 0.15 & 0.40 \\
$P I$ & & 1 & 0.14 & 0.37 \\
$N_{60}$ & & & 1 & 0.41 \\
$K_{s}$ & & & & 1 \\
\hline
\end{tabular}



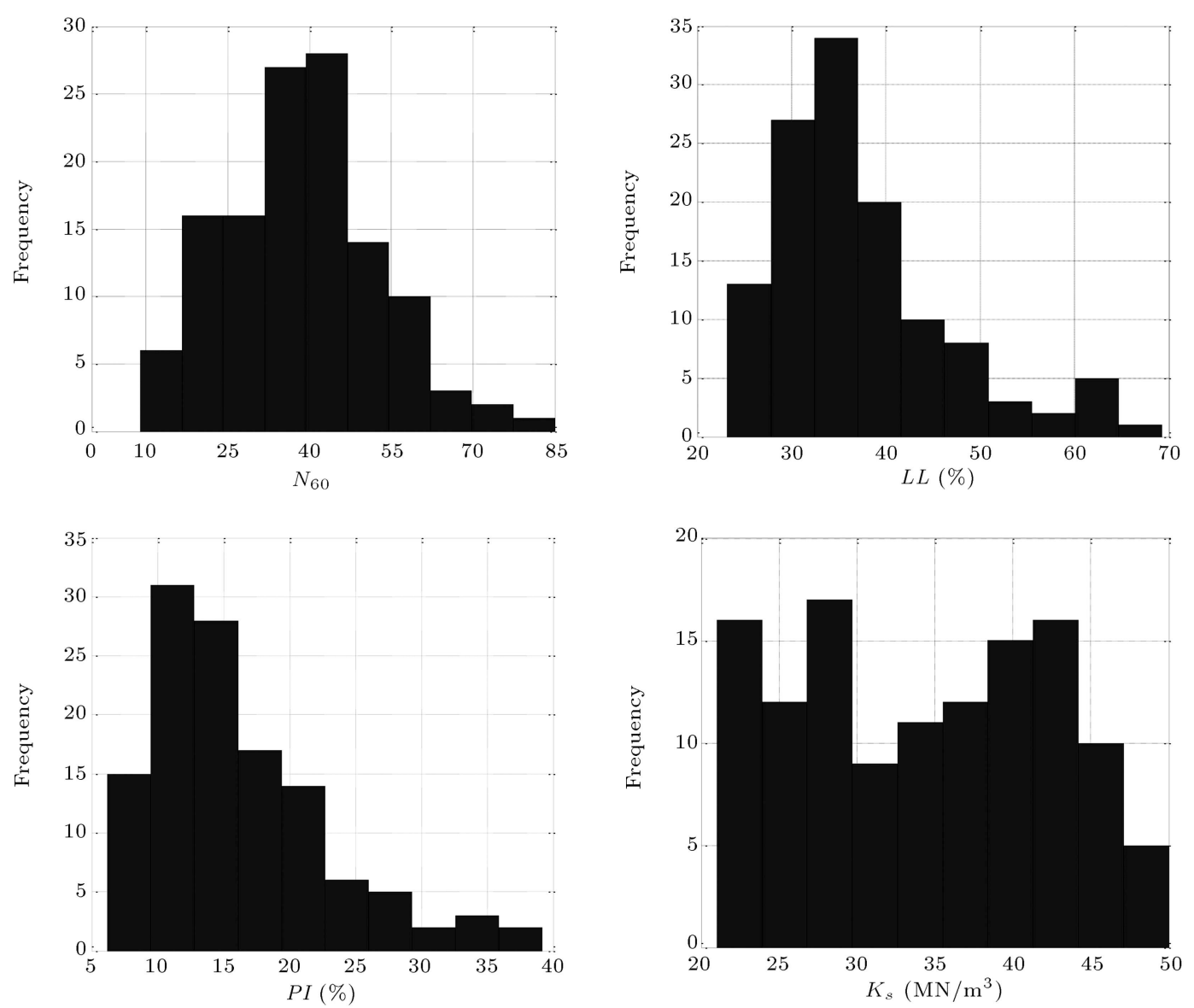

Figure 4. Histograms of the soil parameters.

Table 4. Statistical characteristics of the soil parameters in Group Method Data Handling (GMDH) modeling.

\begin{tabular}{|c|c|c|c|c|c|c|c|}
\hline \multirow{2}{*}{\multicolumn{2}{|c|}{ Parameter }} & \multicolumn{3}{|c|}{ Training (103 data) } & \multicolumn{3}{|c|}{ Testing (20 data) } \\
\hline & & Min. & Ave. & Max. & Min. & Ave. & Max. \\
\hline \multirow{3}{*}{ Input } & $L L(\%)$ & 23.2 & 36.9 & 69.3 & 23.2 & 40.8 & 64.1 \\
\hline & $P I(\%)$ & 6.2 & 15.5 & 39.2 & 7.2 & 19.0 & 34.9 \\
\hline & $N_{60}$ & 9 & 38.9 & 85 & 11 & 37.9 & 77 \\
\hline Output & $K_{s}\left(\mathrm{MN} / \mathrm{m}^{3}\right)$ & 21 & 34.3 & 50 & 21 & 34.1 & 50 \\
\hline
\end{tabular}

In the first part, models without hidden layer were employed to estimate $K_{s}$. Using the no-hidden-layer GMDH models, the model obtained by the combination of $P I$ and $N_{60}$ as input parameters gives the best performance equation as follows:

$$
\begin{aligned}
K_{s}= & 16.45+0.235 N_{60}+0.67 P I-0.0035 N_{60}^{2} \\
& -0.027 P I^{2}+0.018 N_{60} \cdot P I,
\end{aligned}
$$

In Figure 5, the actual output values from the PLT and the predicted curve using the developed no-hiddenlayer model are shown.

In the next part, models with a single hidden layer were adopted to predict $K_{s}$ of clayey soil. Using the single-hidden-layer GMDH models, the model obtained by the combination of variables $N_{60}, L L$, and $P I$ as input parameters has the best performance. Figure 6 shows the structure of the developed single-hiddenlayer model. The polynomials corresponding to this model are as follows:

$$
\begin{aligned}
K_{s}= & 21.43-0.25 N_{60}-0.0005 Y^{2}-0.0033 N_{60}^{2} \\
& +0.021 Y . N_{60} \\
Y= & 27.06+0.058 L L+0.025 P I-0.025 L L^{2} \\
& -0.143 P I^{2}+0.13 L L . P I .
\end{aligned}
$$


Table 5. Statistical results of the proposed models.

\begin{tabular}{lcccc}
\hline \multicolumn{1}{c}{$\boldsymbol{K}_{\boldsymbol{s}}$, model (stage) } & $\boldsymbol{R}^{\mathbf{2}}$ & MAPE & RMSE & MAD \\
\hline$K_{s}$, no-hidden-layer GMDH (training) & 0.96 & 16.36 & 6.67 & 5.61 \\
$K_{s}$, no-hidden-layer GMDH (testing) & 0.96 & 16.84 & 6.68 & 5.74 \\
$K_{s}$, single-hidden-layer GMDH (training) & 0.97 & 16.09 & 6.58 & 5.51 \\
$K_{s}$, single-hidden-layer GMDH (testing) & 0.97 & 15.95 & 6.20 & 5.44 \\
\hline
\end{tabular}

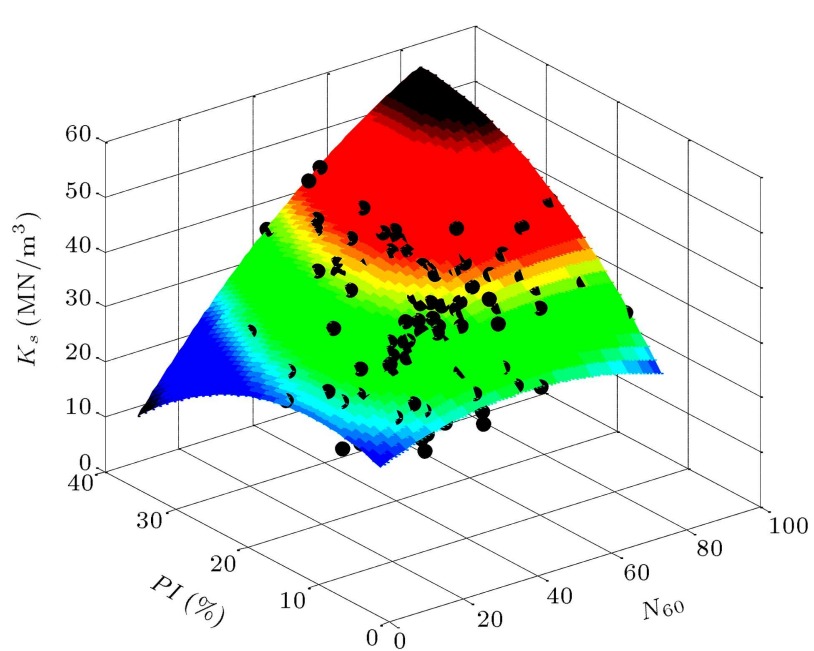

Figure 5. Correlation of $K_{s}$ using Eq. (9).

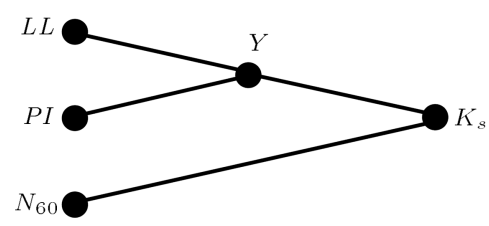

Figure 6. Structure of the developed single-hidden-layer Group Method of Data Handling (GMDH) model.

Figures 7 and 8 show the measured (from PLT) and estimated $K_{s}$ through the training and testing processes. Table 5 shows the capabilities of the proposed models in statistically predicting $K_{s}$ of clayey soil. In this table, MAPE, RMSE, MAD, and $R^{2}$ are respectively the Mean Absolute Percent Error, Root Mean Squared Error, Mean Absolute Deviation, and absolute fraction of variance and their corresponding equations are as follows [48]:

$$
\begin{aligned}
& R^{2}=1-\left[\frac{\sum_{1}^{M}\left(K_{m i}-K_{p i}\right)^{2}}{\sum_{1}^{M}\left(K_{m i}\right)^{2}}\right], \\
& \mathrm{MAPE}=\frac{\sum_{1}^{M}\left|K_{m i}-K_{p i}\right|}{\sum_{1}^{M} K_{m i}} \times 100, \\
& \mathrm{RMSE}=\sqrt{\frac{1}{M} \sum_{1}^{M}\left(K_{m i}-K_{p i}\right)^{2}}, \\
& \mathrm{MAD}=\frac{\sum_{1}^{M}\left|K_{m i}-K_{m i}\right|}{M},
\end{aligned}
$$

where $K_{m i}$ and $K_{p i}$ are the measured and predicted $K_{s}$, respectively.

It can be seen in Table 5 and Figures 7 and 8 that $K_{s}$ of testing data can be estimated with good accuracy by the derived equations. Although the single-hiddenlayer model shows a little better result than the nohidden-layer one does, the no-hidden-layer model is simpler and more generalized than the model with a single hidden layer.

\section{Comparison between the existing and developed equations}

In order to evaluate accuracy of the proposed GMDHbased equations to predict $K_{s}$, a comparison between their behavior and the previously proposed relationships applying the whole data set has been made and

\begin{tabular}{|c|c|c|c|c|c|c|}
\hline Equation & Eq. no. & Reference & $R^{2}$ & MAPE & RMSE & MAD \\
\hline$K_{s}\left(\mathrm{MN} / \mathrm{m}^{3}\right)=1.17 N_{55}+17.6$ & $(15)$ & Bowles [29] & 0.08 & 96.03 & 36.61 & 32.88 \\
\hline$K_{s}\left(\mathrm{MN} / \mathrm{m}^{3}\right)=1.2 N_{60}+6.07$ & $(16)$ & Webb $[58]$ & 0.54 & 56.52 & 23.84 & 19.35 \\
\hline$K_{s}\left(\mathrm{MN} / \mathrm{m}^{3}\right)=1.1 N_{55}+6.6$ & $(17)$ & Bowles [29] & 0.52 & 57.81 & 24.26 & 19.79 \\
\hline$K_{s}\left(\mathrm{MN} / \mathrm{m}^{3}\right)=0.622 N_{60}$ & $(18)$ & Behpoor and Ghahramani [59] & 0.85 & 34.29 & 13.6 & 11.74 \\
\hline$K_{s}\left(\mathrm{MN} / \mathrm{m}^{3}\right)=0.96 N_{60}$ & $(6)$ & Naeini et al. [30] & 0.87 & 28.09 & 12.76 & 9.62 \\
\hline No-hidden-layer GMDH & $(9)$ & This study & 0.96 & 16.44 & 6.67 & 5.63 \\
\hline Single-hidden-layer GMDH & $(10)$ & This study & 0.97 & 16.07 & 6.53 & 5.50 \\
\hline
\end{tabular}
presented in Table 6. Among the equations presented in the past, the equations proposed by Naeini et al. [30]

Table 6. Statistical results for the $K_{s}$ equations. 


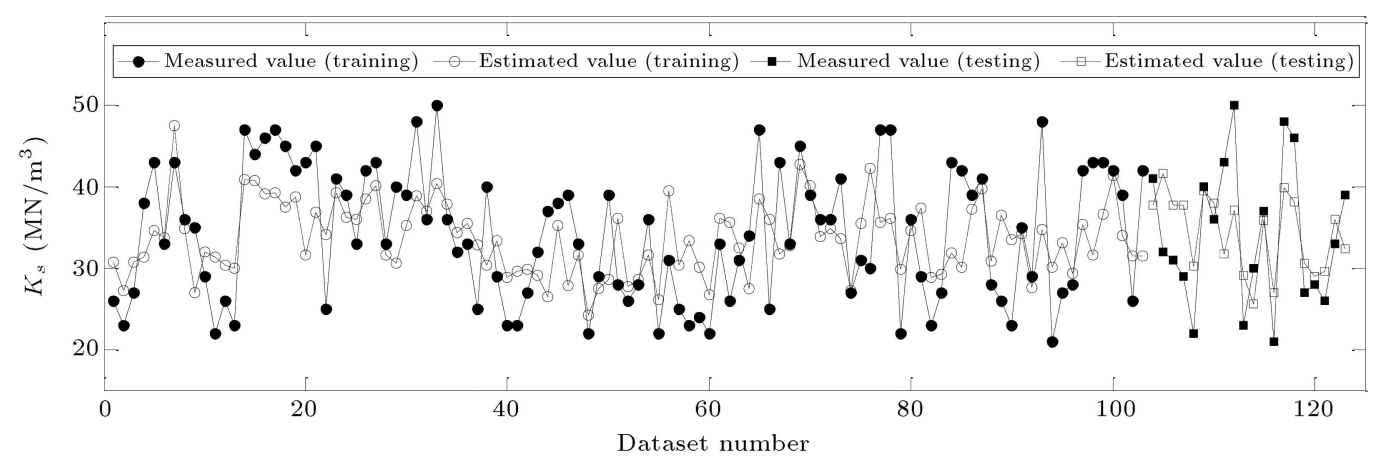

Figure 7. Comparison between actual and predicted $K_{s}$ values using no-hidden-layer model.

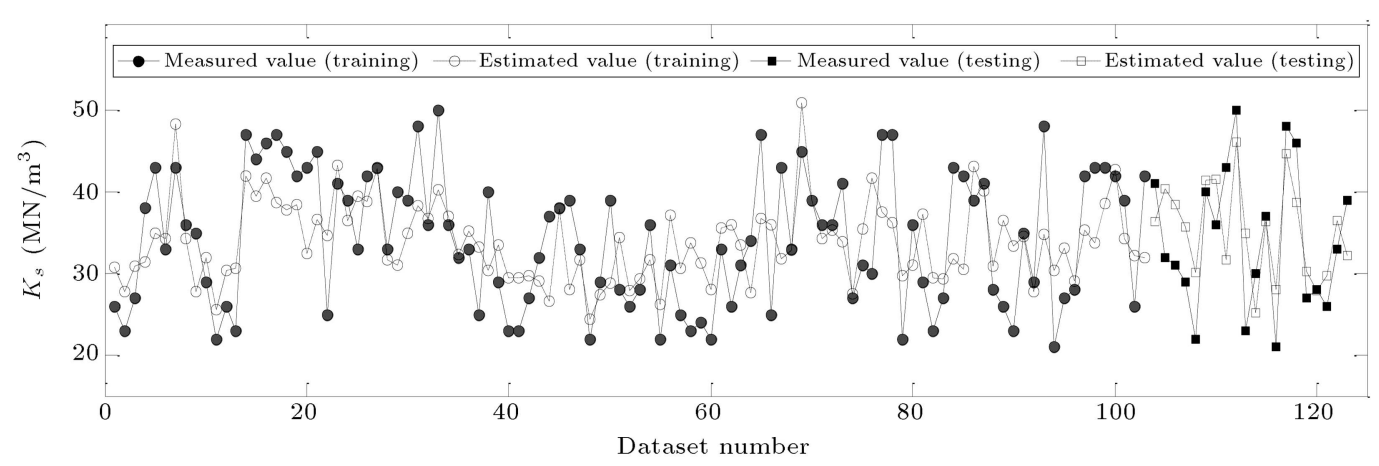

Figure 8. Comparison between actual and predicted $K_{s}$ values using single-hidden-layer model.

(Eq. (6) in Table 6) have the highest $R^{2}(0.87)$ and the lowest MAPE (28.09), RMSE (12.76), and MAD (9.62). MAPE, RMSE, and MAD have the lowest values in both single-hidden-layer and no-hidden-layer GMDH models. Therefore, the developed models to predict $K_{s}$ have a better performance than the existing equations. The single-hidden-layer GMDHbased equation (Eq. (10)) is the most accurate equation and, by using it, $K_{s}$ of clayey soil in the studied area can be accurately estimated.

Figure 9 gives a graphical representation of the accuracy of the proposed models compared with the existing relationships by drawing the scaled relative error $\left(E_{r}\right)$ versus Scaled Cumulative Frequency (SCF).

$$
E_{r}(\%)=\frac{\left(K_{p i}-K_{m i}\right)}{K_{m i}} \times 100 .
$$

According to Figure 9, a wide range of errors in estimating $K_{s}$ of clayey soil occurs with equations presented in the past compared with the GMDHbased equations. As a result, the equations obtained through the GMDH polynomial NN approach to the prediction of $K_{s}$ of clayey soil are more accurate than those achieved by all of the other existing equations.

It should be noted that the relationships presented in this study are applicable to the calculation of $K_{s}$ for small plates (with the side dimension of $B=0.305 \mathrm{~m}$ ) and the values should be modified for

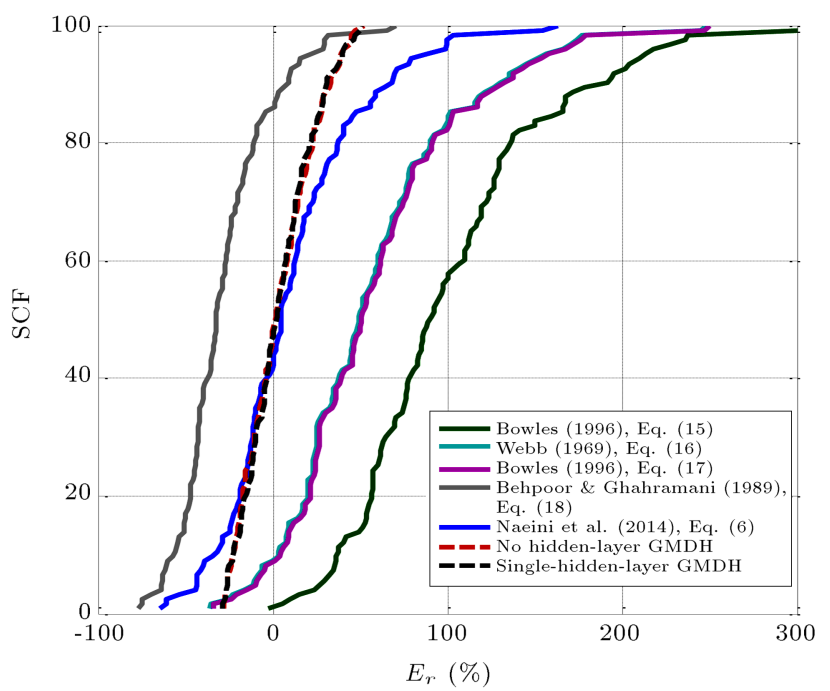

Figure 9. Graphical representation of the accuracy of equations for prediction of $K_{s}$.

size effects before they become applicable to general foundation problems.

\section{Sensitivity analysis}

Because the proposed models to predict $K_{s}$ of clayey soil are complex and the effect of input parameters on the output is not clear, a sensitivity analysis has been carried out to evaluate the effect of each input 

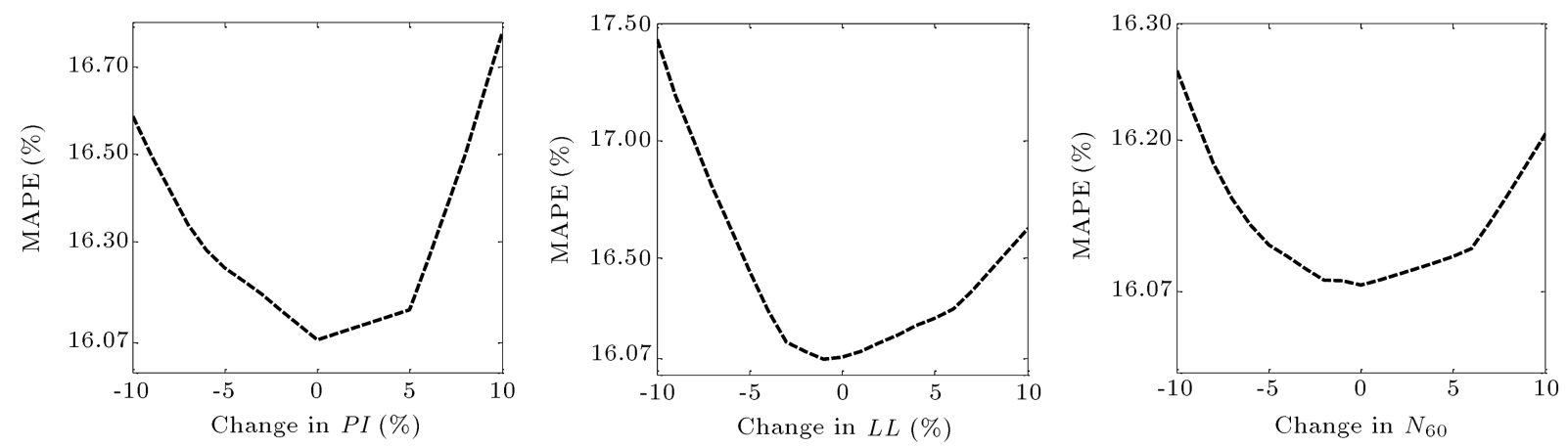

Figure 10. Effect of changes in input parameters on the output error.

parameter on the output. In the present study, sensitivity analysis of the single-hidden-layer GMDH model was carried out by changing each of the input parameters at a constant rate, one at a time, while other input parameters were constant [49]. The rate of constant change of $-10 \%$ to $10 \%$ was used. With the change in every input variable, MAPE in the output $\left(K_{s}\right)$ was determined (Figure 10). In Figure 10, it can be seen that $K_{s}$ of clayey soil is significantly affected by variations in the $L L$ value and MAPE increases significantly compared with $P L$ and $N_{60}$. For instance, a $10 \%$ error in measuring $L L$ may result in approximately $17.43 \%$ error $(\mathrm{MAPE}=17.43)$ in estimating $K_{s}$ by the GMDH-based equation (Eq. (9)). Also, $10 \%$ variation in $P I$ and $N_{60}$ may result in the MAPE of approximately 16.78 and 16.26 , respectively. Accordingly, higher precision is required in determining $L L$ than in determining the two other parameters.

\section{Conclusions}

In this study, an attempt was made to estimate the clayey soil subgrade reaction modulus $\left(K_{s}\right)$ by the Group Method of Data Handling (GMDH)-type Neural Network (NN) simulation using a database consisting of 123 data sets from Qazvin, Iran. In addition, a sensitivity analysis of the best obtained model was carried out to determine the effect of input parameters on predicted $K_{s}$. The results showed that the $K_{s}$ predicted by GMDH-based equations was in good agreement with the $K_{s}$ obtained by the Plate Load Tests (PLTs). Therefore, reliable estimation abilities were achieved by GMDH approach. The GMDHderived equations were much more accurate than the available equations. The developed single-hidden-layer model showed a little better result than the no-hiddenlayer one did. However, the no-hidden-layer model was simpler and more generalized than the model with a single hidden layer.

The result of the sensitivity analysis showed that $K_{s}$ of clayey soil was significantly affected by the variation in the Liquid Limit $(L L)$ value. Thus, the determination of $L L$ required more precision than two other parameters $\left(N_{60}\right.$ and Plastic Index $\left.(P I)\right)$.

Here, it should be noted that the models presented in this study and their corresponding equations were derived using a limited type of soil (clayey soil) within the range of $21 \leq 21 \leq 50 \mathrm{MN} / \mathrm{m}^{3}$. Accordingly, further studies of the other types of soil are needed to verify validity of the equations.

\section{Nomenclature}

\begin{tabular}{|c|c|}
\hline$B$ & Plate dimension \\
\hline$E_{s}$ & Modulus of elasticity \\
\hline FDD & Field Dry Density \\
\hline FMC & Field Moisture Content \\
\hline$i$ & $\begin{array}{l}\text { Number of the value considered in } \\
\text { cumulative probability } P\end{array}$ \\
\hline$K_{m i}$ & Actual measured $K_{s}$ output \\
\hline$K_{p i}$ & Predicted $K_{s}$ output \\
\hline$K_{s}$ & Subgrade reaction modulus \\
\hline$L L$ & Liquid Limit \\
\hline$M$ & Total number of data sets \\
\hline MAD & Mean Absolute Deviation \\
\hline MAPE & Mean Absolute Percent Error \\
\hline MDD & Maximum Dry Density \\
\hline$N$ & Standard penetration test blow counts \\
\hline$N_{60}$ & Corrected $N$ \\
\hline$n$ & Total number of input variables \\
\hline $\mathrm{OMC}$ & Optimum Moisture Content \\
\hline$P I$ & Plastic Index \\
\hline$q_{a}$ & Allowable bearing capacity \\
\hline$R^{2}$ & Absolute fraction of variance \\
\hline RMSE & Root Mean Square Error \\
\hline$\Delta s$ & $\begin{array}{l}\text { Settlement produced by load } \\
\text { application }\end{array}$ \\
\hline $\mathrm{SF}$ & Safety Factor \\
\hline$Y$ & Input variable \\
\hline$y$ & Actual output \\
\hline
\end{tabular}


Applied pressure to the bearing plate

$v$

$$
\text { Poisson's ratio }
$$

\section{References}

1. Sharma, L.K., Umrao, R.K., Singh, R., Ahmad, M., and Singh, T.N. "Geotechnical characterization of road cut hill slope forming unconsolidated geo-materials: a case study", Geotech. Geol. Eng., 35(1), pp. 503-515 (2017).

2. Sharma, L.K., Umrao, R.K., Singh, R., Ahmad, M., and Singh, T.N. "Stability investigation of hill cut soil slopes along National highway 222 at Malshej Ghat, Maharashtra", J. Geol. Soc. India, 89(2), pp. 165-174 (2017).

3. Singh, T.N., Singh, R., Singh, B., Sharma, L.K., Singh, R., and Ansari, M.K. "Investigations and stability analyses of Malin village landslide of Pune district, Maharashtra, India", Nat. Hazards, 81(3), pp. 20192030 (2016).

4. Winckler, E., Die Lehre von Elastizitat und Festigkeit (On elasticity and fixity), Prague, p. 182 (1867).

5. Farouk, H. and Farouk, M. "Effect of elastic soil structure interaction on modulus of subgrade reaction", In Recent Advances in Material, Analysis, Monitoring, and Evaluation in Foundation and Bridge Engineering, pp. 111-118 (2014).

6. Vesic, A.S. "Bending of beams resting on isotropic solids", Journal of the Engineering Mechanics Division, 87(2), pp. 35-53 (1961).

7. Biot, M.A. "Bending of an infinite beam on an elastic foundation", J. Appl. Mech. (Trans. ASME), 4, pp. A1-A7 (1937).

8. Iskander, G.M. and Gabr, R.H. "Soil-pipe interaction due to tunneling: comparison between Winkler and elastic continuum solutions", Internet (2009).

9. Klar, A., Vorster, T.E.B., Soga, K., and Mair, R.J., Soil-Pipe-Tunnel Interaction: Comparison Between Winkler and Elastic Continuum Solutions, Department of Engineering, University of Cambridge, UK, pp. 1-14 (2004).

10. Basudhar, P.K., Yadav, S.K., and Basudhar, A. "Treatise on Winkler modulus of subgrade reaction and its estimation for improved soil-structure interaction analysis", Geotech. Geol. Eng., 36(5), pp. 3091-3109 (2018).

11. Farouk, H. and Farouk, M. "Calculation of subgrade reaction modulus considering the footing-soil system rigidity", In Vulnerability, Uncertainty, and Risk: Quantification, Mitigation, and Management, pp. 2498-2507 (2014).

12. Terzaghi, K.V. "Evaluation of coefficient of subgrade reaction", Geotechnique, 5(4), pp. 297-326 (1955).

13. Moayed, R.Z. and Janbaz, M. "Foundation size effect on modulus of subgrade reaction in clayey soil", Electronic Journal of Geotechnical Engineering, 13, pp. 18 (2018).
14. Teodoru, I.B. and Toma, I.O. "Numerical analyses of plate loading test", Buletinul Institutului Politehnic din lasi. Sectia Constructii, Arhitectura, 55(1), p. 57 (2009).

15. Elsamny, K., Elsedeek, M.B., and AbdElsamee, W.N. "Effect of depth of foundation on modulus of elasticity 'ES' for Cohessionless soil", Civil Engineering Researches Magazine of Al-Azhar University, 32(3), p. 938 (2010).

16. Marto, A., Latifi, N., Janbaz, M., Kholghifard, M., Khari, M., Alimohammadi, P., and Banadaki, A.D. "Foundation size effect on modulus of subgrade reaction on sandy soils", Electronic Journal of Geotechnical Engineering, 17, pp. 2523-2530 (2012).

17. Imanzadeh, S., Denis, A., and Marache, A. "Settlement uncertainty analysis for continuous spread footing on elastic soil", Geotech. Geol. Eng., 33(1), pp. 105-122 (2015).

18. Naeini, S.A. and Hossein Zade, M.H. "Numerical study of modulus of subgrade reaction in eccentrically loaded circular footing resting", World Academy of Science, Engineering and Technology, International Journal of Civil, Environmental, Structural, Construction and Architectural Engineering, 11(1), pp. 11-14 (2017).

19. Boulanger, R.W., Curras, C.J., Kutter, B.L., Wilson, D.W., and Abghari, A. "A seismic soil-pile-structure interaction experiments and analysis", J. Geotech. Geoenvironm. Eng., 125, pp. 750-759 (1999).

20. Daloglu, A.T. and Vallabhan, C.V.G. "Values of $k$ for slab on winkler foundation", J. Geotech. Geoenvironm. Eng., 126(5), pp. 463-471 (2000).

21. Allotey, N. and El Nagger, M.H. "Generalized dynamic Winkler model for nonlinear soil-structure interaction analysis", Can. Geotech. J., 45, pp. 560-573 (2008).

22. Hernandez, O., El Naggar, H., and Bischoff, P.H. "Soilstructure interaction of steel fiber reinforced concrete slab strips on a geogrid reinforced subgrade", Geotech. Geol. Eng., 33(3), pp. 727-738 (2015).

23. Prendergast, L.J. and Gavin, K. "A comparison of initial stiffness formulations for small-strain soil-pile dynamic Winkler modeling", Soil Dyn. Earthq. Eng., 81, pp. 27-41 (2016).

24. Dinçer, I. "Models to predict the deformation modulus and the coefficient of subgrade reaction for earth filling structures", Adv. Eng. Soft., 42(4), pp. 160-71 (2011).

25. Naeini, S.A. and Taherabadi, E. "Numerical and theoretical study of plate load test to define coefficient of subgrade reaction", Journal of Geotechnical and Transportation Engineering, 1(2), p. 2 (2015).

26. Patil, N.N., Swamy, H.R., and Shivashankar, R. "Studies on modulus of subgrade reaction of reinforced foundation soil using model plate load test", Journal of Chemical and Pharmaceutical Sciences, Special Issue 2, p. 2115 (2016).

27. Guo, W., Kou, H., Zhou, B., Nie, W., and Chu, J. "Simplified methods to analyze geosynthetic mattress resting on deformable foundation soil", Marine Georesources Geotechnology, 35(3), pp. 339-345 (2017). 
28. Scott, R.F., Foundation Analysis, Englewood Cliffs, NJ, Prentice Hall (1981).

29. Bowles, J.E., Foundation Analysis and Design, McGraw-Hill Book Company (1966).

30. Naeini, S.A., Ziaie Moayed, R., and Allahyari, F. "Subgrade reaction modulus $\left(K_{s}\right)$ of clayey soils based on field tests", Journal of Engineering Geology, 8(1), pp. 2021-2046 (2014).

31. Kalantary, F. and Kordnaeij A. "Prediction of compression index using artificial neural network", Sci. Res. Essays, 7(31), pp. 2835-2848 (2012).

32. Erzin, Y. and Turkoz, D. "Use of neural networks for the prediction of the CBR value of some Aegean sands", Neural Comput. Appl., 27(5), pp. 1415-1426 (2016).

33. Sharma, L.K., Singh, R., Umrao, R.K., Sharma, K.M., and Singh, T.N. "Evaluating the modulus of elasticity of soil using soft computing system", Eng. Comput., 33(3), pp. 497-507 (2017).

34. Singh, R., Umrao, R.K., Ahmad, M., Ansari, M.K., Sharma, L.K., and Singh, T.N. "Prediction of geomechanical parameters using soft computing and multiple regression approach", Measurement, 99, pp. 108-119 (2017).

35. Asvar, F., Shirmohammadi Faradonbeh, A., and Barkhordari, K. "Predicting potential of controlled blasting-induced liquefaction using neural networks and neuro-fuzzy system", Sci. Iran., 25(2), pp. 617631 (2018).

36. Tekin, E. and Akbas, S.O. "Predicting groutability of granular soils using adaptive neuro-fuzzy inference system", Neural Comput. Appl., 31(4), pp. 1091-1101 (2019).

37. Ataee, O., Hafezi Moghaddas, N., Lashkaripour, G.R., and Jabbari Nooghabi, M. "Predicting shear wave velocity of soil using multiple linear regression analysis and artificial neural networks", Sci. Iran., 25(4), pp. 1943-1955 (2018).

38. Erzin, Y. and Ecemis N. "The use of neural networks for the prediction of cone penetration resistance of silty sands", Neural Comput. Appl., 28(1), pp. 727736 (2017).

39. Xue, X. and Xiao, M. "Application of adaptive neurofuzzy inference system for prediction of internal stability of soils", Eur. J. Environ. Civ. Eng., 23(2), pp. 153-171 (2019).

40. Sharma, L.K., Vishal, V., and Singh, T.N. "Developing novel models using neural networks and fuzzy systems for the prediction of strength of rocks from key geomechanical properties", Measurement, 102, pp. 158-169 (2017).

41. Ranasinghe, R.A.T.M., Jaksa, M.B., Kuo, Y.L., and Nejad, F.P. "Application of artificial neural networks for predicting the impact of rolling dynamic compaction using dynamic cone penetrometer test results", Journal of Rock Mechanics and Geotechnical Engineering, 9(2), pp. 340-349 (2017).
42. Sharma, L.K., Vishal, V., and Singh, T.N. "Predicting $\mathrm{CO}_{2}$ permeability of bituminous coal using statistical and adaptive neuro-fuzzy analysis", J. Nat. Gas. Sci. Eng., 42, pp. 216-225 (2017).

43. Mohammadzadeh, D., Bazaz, J.B., and Alavi, A.H. "An evolutionary computational approach for formulation of compression index of fine-grained soils", Eng. Appl. Artif. Intell., 33, pp. 58-68 (2014).

44. Ivakhnenko, A.G. "Polynomial theory of complex systems", IEEE. Trans. Syst. Man. Cybern., 1(4), pp. 364-378 (1971).

45. Farlow, S.J., Self-Organizing Method in Modelling: GMDH Type Algorithm, Marcel Dekker Inc, New York (1984).

46. Eslami, A., Mola-Abasi, H., and Tabatabaeishorijeh, P. "A polynomial model for liquefaction potential prediction from CPT data", Sci. Iran., 21(1), pp. 4452 (2014).

47. Mola-Abasi, H., Eslami, A., and Tabatabaeishorijeh, P. "Shear wave velocity by polynomial neural networks and genetic algorithms based on geotechnical soil properties", Arab. J. Sci. Eng., 38(4), pp. 829-838 (2013).

48. Kordnaeij, A., Kalantary, F., Kordtabar, B., and Mola-Abasi, H. "Prediction of recompression index using GMDH-type neural network based on geotechnical soil properties", Soils Found., 55(6), pp. 1335-1345 (2015).

49. Ziaie Moayed, R., Kordnaeij, A., and Mola-Abasi, H. "Compressibility indices of saturated clays by group method of data handling and genetic algorithms", Neural Comput. Appl., 28(1), pp. 551-564 (2017).

50. Ardakani, A. and Kordnaeij, A. "Soil compaction parameters prediction using GMDH-type neural network and genetic algorithm", Eur. J. Environ. Civ. Eng., 23(4), pp. 449-462 (2019).

51. Hassanlourad, M., Ardakani, A., Kordnaeij, A., and Mola-Abasi, H. "Dry unit weight of compacted soils prediction using GMDH-type neural network", The European Physical Journal Plus, 132 (8), p. 357 (2017).

52. Moayed, R.Z., Kordnaeij, A., and Mola-Abasi, H. "Pressuremeter modulus and limit pressure of clayey soils using GMDH-type neural network and genetic algorithms", Geotech. Geol. Eng., 36(1), pp. 165-178 (2018).

53. Naeini, S.A., Moayed, R.Z., Kordnaeij, A., and MolaAbasi, H. "Elasticity modulus of clayey deposits estimation using group method of data handling type neural network", Measurement, 121, pp. 335-343 (2018).

54. Reznik, Y.M. "Influence of physical properties on deformation characteristics of collapsible soils", Eng. Geol., 92(1), pp. 27-37 (2007).

55. Lee, J. and Jeong, S. "Experimental study of estimating the subgrade reaction modulus on jointed rock foundations", Rock Mech. Rock Eng., 49(6), pp. 20552064 (2016). 
56. Reznik, Y.M. "Plate-load tests of collapsible soils", $J$. Geotech. Eng., 119(3), pp. 608-15 (1993).

57. Moayed, R.Z. and Janbaz, M. "Subgrade reaction modulus of Tehran alluvium", P. I. Civil Eng-Geotec, 164(4), pp. 283-288 (2011).

58. Webb, D.L. "Settlement of structures on deep alluvial sandy sediments in Durban", South Africa Proceedings, Conference on in Situ Behavior of Soil and Rock, Institution of Civil Engineers, London, pp. 181-188 (1969).

59. Behpoor, L. and Ghahramani, A. "Correlation of SPT to strength and modulus of elasticity of cohesive soils", 12th International Conference on Soil Mechanics and Foundation Engineering, ISSMFE, Rio do Janeiro, Brazil, pp. 175-178 (1998).

60. ASTM D1194 "Standard test method for bearing capacity of soil for static load and spread footings", ASTM Int. (1994).

61. ASTM D1586 "Standard test method for Standard Penetration Test (SPT) and split-barrel sampling of soils", ASTM Int. (2011).

62. Sivrikaya, O. and Toğrol, E. "Determination of undrained strength of fine-grained soils by means of SPT and its application in Turkey", Eng. Geol., 86(1), pp. 52-69 (2006).

63. Clayton, C.R.I. "The Standard Penetration Test (SPT): Methods and use", Construction Industry Research and Information Association Report, CIRIA, London, 143 (1995).

64. McGregor, J. and Duncan, J.M. "Performance and use of the standard penetration test in geotechnical engineering practice", Report of CGPR. Virginia Polytechnic Institute and State University, Virginia (1998).

65. Saran, S., Analysis and Design of Substructures, Balkema, Rotterdam (1996).

66. ASTM D422-63 "Standard test method for particlesize analysis of soils", ASTM Int. (2007).

67. ASTM D4318 "Standard test methods for liquid limit, plastic limit, and plasticity index of soils", ASTM Int. (2010).

\section{Biographies}

Seyed Abolhasan Naeini received his $\mathrm{PhD}$ degree in Geotechnical Engineering from Iran University of Science and Technology in 2000 and is currently a Professor in Geotechnical Engineering at Imam Khomeini International University, Qazvin, Iran. His research interests include soil improvement, soil reinforcement, unsaturated soils, cone penetration test, soil behavior under static and cyclic loading, earthquake engineering, and liquefaction. He has had numerous papers published in national and international journals and conferences in these areas.

Reza Ziaie Moayed received his $\mathrm{PhD}$ degree in Geotechnical Engineering from Iran University of Science and Technology in 2001 and is currently an Associate Professor in Geotechnical Engineering at Imam Khomeini International University, Qazvin, Iran. His research interests include soil improvement techniques, soil dynamics, geotechnical earthquake engineering, liquefaction, cone penetration test, monotonic and cyclic triaxial testing, embankment dam engineering, and pile testing and design. He has 50 journal papers and 95 conference papers.

Afshin Kordnaeij received his MS degree in Geotechnical Engineering from the University of Guilan, Iran, in 2006 and is currently a PhD graduated in Geotechnical Engineering at Imam Khomeini International University, Qazvin, Iran. His research interests include soft computing in geotechnical engineering and soil improvement with special focus on grouting.

Hossein Mola-Abasi received his MSc in Geotechnical Engineering from the University of Guilan in 2010. He is currently a PhD graduated in Geotechnical Engineering at Babol University of Technology. His research interests are mainly in the area of soft computing in geomechanics with special focus on earthquake geotechnical en gineering and dynamic behavior of soils, and more recently on soil improvement techniques. 